\title{
Ecological aspects in assessment of acoustic pollution at the territory of Rostov-on-Don
}

\author{
Svetlana Sheina ${ }^{1}$, Albina Fedorovskaya ${ }^{1 *}$ \\ ${ }^{1}$ Don State Technical University, Gagarin square 1, Rostov-on-Don, 344000, Russia
}

\begin{abstract}
Dynamic changes of urban environment determined by fulfillment of multiple residential and public edifices, reclamation of vast spaces, massive reformation of former industrial, warehouse and port edifices, carry considerable possibilities for current formation of architecture and urbanization of spaces of increased comfort with optimal functional organization. Article is devoted to environmental aspects of territory acoustic pollution assessment in Rostov-on-Don.
\end{abstract}

\section{Introduction}

The National urban development doctrine of the Russian Federation and Sustainable Development Strategy state the priorities related to the achievement of interconnected socioeconomic and spatial development of the Russian cities alongside with the maximal preservation and rational utilization of natural resources. Special attention is given to joining the efforts of the specialists engaged in urban development, in creating a balanced and comfortable urban environment. The life quality is directly attributed to the activities of such specialists whose purpose is to create the environment for the reasons of improvement of life conditions for not merely the current generation but also for the consequent generations of the population.

Creation of a comfortable urban environment is only possible under a balanced development of territories with regard to the needs of population and the possibilities of subnational entities. It should be noted that comprehensive socioeconomic and environmental feasibility studies must be carried out while making urban planning decisions $[1,2]$.

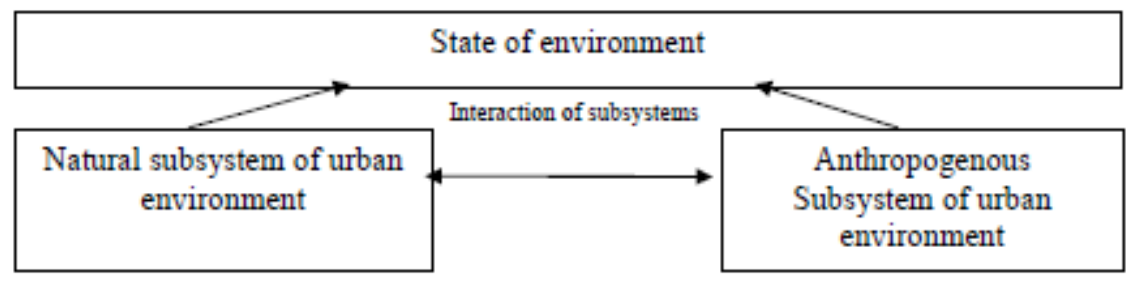

Fig. 1. Influence of natural and anthropogenous subsystems within the urban system on the state of environment

${ }^{*}$ Corresponding author: bina-87@mail.ru 
The state of environment is determined by the interaction between of natural and anthropogenous subsystems within the urban system; adverse effects of such interaction entail environmental problems: pollution of atmosphere and water, soil and plants degeneration, solid household waste disposal, etc.

\section{Experimental section}

An issue of the urban environment quality regardless to whether the environment is created in the free spaces or within the formerly reclaimed spaces with reassignment of purpose thereof is becoming one of the most crucial ones. Based on the state of environment, optimal structure and the balance between the natural and manufactured components thereof once can estimate the sustainability of environment.

An objective necessity of elaboration of a system for multi-criteria assessment of urban environment quality in order to identify the existing problems of the urban area and to prepare a set of solutions and measures aimed at elimination thereof. It becomes possible to elaborate a steady development concept for the urban area based on the multi-criteria assessment thereof. The urban environment quality assessment must be carried out from the viewpoint of a dynamically developing and complex system the elements of which are interconnected and interdependent.

The quality of the urban environment depends at large on the project decisions made in the course of urban planning, on the functional purpose of objects placed therein, and on the actual use of these objects. Creation of a comfortable, steadily developing urban environment under consideration of all components thereof: natural objects and components of natural environment - is an important task.

An assessment procedure for urban living environment was established by the Order of the Ministry of Regional Development of Russia No. 371 dd. September 9, 2013. The established procedure was based on a constant set of values (indicators) that distinguish various aspects of the urban environment. Calculation of values underlying the rating is made with the use of a number of statistical and mathematical methods.

41 indicator has been selected for the urban living environment; these indicators fall into blocks containing 13 indexes each; these are used to obtain a general city attractiveness index (GCAI). Following are the indexes reflecting the main trends in assessment of urban living environment quality:

- population number dynamics;

- transport infrastructure;

-state of natural environment;

-access to housing;

-development of housing sector;

-demographic features of population;

-innovative activities;

-utility infrastructure;

-workforce capacity;

-social infrastructure;

-social parameters of community;

-welfare of citizens;

-urban economics [2].

In this case, the city is viewed as a territorial formation, the planning structure of which determines the living and socialization environment for the population on which, in its turn, the further development of urban territory depends. A range of economic, environmental and social factors act as criteria for urban territory assessment. Natural environment state 
has a significant role. To assess the environmental state, it is proposed to review the following block of indicators shown in Table 1.

The problem of noise pollution takes one of the leading places among the environmental issues of large cities. Currently, over $20 \%$ of urban population in developed countries including Russia, suffer from increased noise exposure which has and adverse effect on human health. The scale of noise pollution and its trend to grow in the Russian Federation cause concern and demand prompt measures to be taken.

Table 1 Assessment criteria for urban environment

\begin{tabular}{|c|c|c|}
\hline & Group of criteria & Criterion \\
\hline \multirow{5}{*}{1.1} & \multirow{5}{*}{$\begin{array}{l}\text { Quality of environment } \\
\text { assessed under hygienic and } \\
\text { environmental norms }\end{array}$} & Ambient air \\
\hline & & Drinking water \\
\hline & & Fire points \\
\hline & & Electromagnetic fields \\
\hline & & Noise \\
\hline \multirow{4}{*}{1.2} & \multirow{4}{*}{ Supply of resources } & Parklands, forested areas \\
\hline & & Water bodies (as wastewater inlets) \\
\hline & & Ambient air (as exhaust inlet) \\
\hline & & Grounds for landfilling \\
\hline
\end{tabular}

The noise is an unpleasant, unwanted sound or a combination of such sounds preventing a comfortable perception of useful information, having an irritating effect and an adverse effect on the regular rhythm of human life [3]. Noise elevation over the established normative values as well as a lasting exposure to excessive noise have a negative influence on human health: causes sleep disturbances, affects nervous and cardiovascular systems. This factor provokes stress situations, quick lassitude, and this in its turn has a direct effect on working capacity and emotional state of human.

According to the provisions of sanitary norms SN 2.2.4/2.1.8.562-96, the allowable exposure limits of noise before facades of the first estate development front, $\mathrm{L}_{\text {Aequiv. }}=55$ $\mathrm{dBA}$ at daytime, and $\mathrm{L}_{\text {Aequiv. }}=45 \mathrm{dBA}$ (not more than) at night, and not more than $\mathrm{L}_{\text {Aequiv. }}$. $=45 \mathrm{dBA}$ in the yard at both day and night [4].

The issue of noise pollutions is also crucial for the city of Rostov-on-Don. In the course of the last years, a complex acoustic situation determined by excessive levels of sound in practically every area, i.e., residential, industrial, and recreational areas, has formed. The city of Rostov-on-Don is distinguished by dense development, high intensity of transport highways and utilities. Vehicle fleet is steadily growing, mainly due to personal vehicles. The share of vehicles with considerable term of operation is growing, these vehicles have exhausted their performance potential, and are one of the most adverse as of acoustic characteristics [7]. The acoustic situation is further worsened by the presence of a functioning airport within the city limits. In the course of research, in-situ measurements of noise pollution level with «Noise level meter-003-M3» device were carried out in the city of Rostov-on-Don.

\section{Results section}

On the first stage, the planning structure of the city was analyzed, and the sampling points were selected, as per requirements of GOST 20444-85 and GOST 23337-78* standards. With the help of ArcGIS 10.1 application, a map of the main noise sources located within the city was prepared [5], with plotting of sampling points (see Fig. 2). 


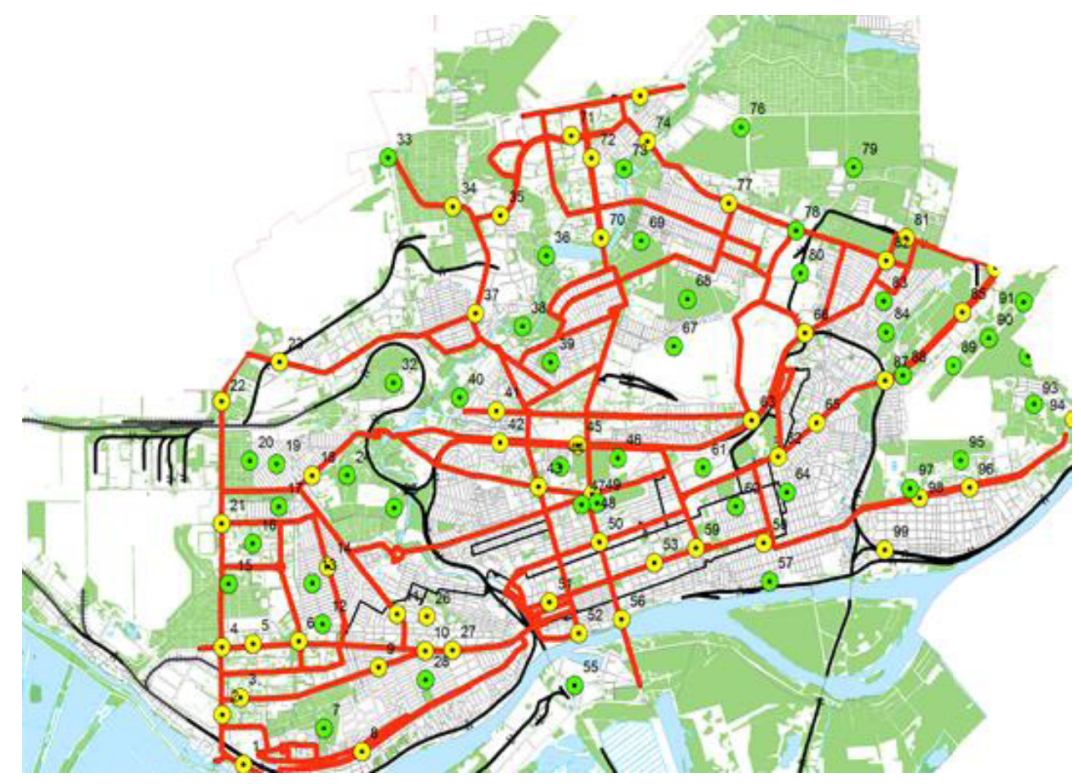

Fig. 2. Map of main noise sources

On the second stage, the actual noise levels were determined at the selected points. Based on the results of the experiment, a map of noise pollution density of the Rostov-onDon city territory was created in the ArcGIS ESRI environment (see Fig. 3).

The results of in-situ measurements allowed to draw a conclusion that the maximal noise levels were registered on the main streets of the cities. Average volume of traffic reaches 2000-3000 and more transport units per hour, and the maximal noise levels are at 90-95 dBA. Noise level excess as compared to normative values is 15-20 dBA.

The experiment performed allowed to distinguish the zones of acoustic discomfort represented by the Avenues: Mikhaila Nagibina, Stachki, Voroshilovskiy, Budennovskiy, Kosmonavtov, Sholokhova, and the Squares: Lenina, Gagarina, Streets: Krasnoarmeyskaya, Malinovskogo, Vyatskaya.

Thus, the acoustic discomfort zones are mainly formed in the proximity of traffic thoroughfares; likewise the territory of the so-called "old Rostov" is under stress. To solve the problem of noise pollution within the city limits, the planning analysis within the acoustic discomfort is necessary. Elaboration of noise protection measures and efficiency assessment of integration of corresponding edifices into the urban landscape are required.

It has to be noted that the reasons of acoustic discomfort are not only related to surface transport arrangement but also to nowadays irrational examples of old housing development which clearly do not comply with the modern norms and rules of urban development: the streets are narrow and divide the urban area into small-sized blocks thus forming many crossroads on the same level $[6,8]$. Once the noise pollution density map is compared to the living amenity map of Rostov-on-Don, it becomes obvious that the zones dangerous for health overlap the zones of active noise pollution. This fact confirms an essential contribution of noise pollution value to the assessment of the urban environment state and amenity o living. 
a)

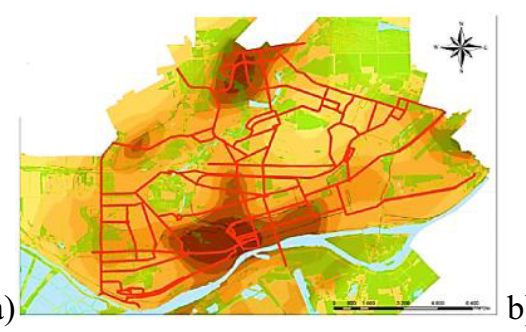

b)

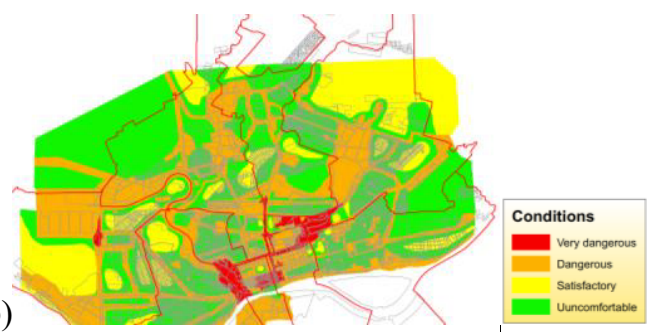

Fig. 3. a) Map of noise pollution density in Rostov-on-Don; b) Assessment of environmental amenity of living

Ecological arrangement of urban environment is a specific sphere of activity aimed at achievement and sustenance of quality of the environment components at the level corresponding to established standards.

\section{Conclusions}

Urban development aspect of management is aimed at making decisions on arrangement of territorial system which intend to preserve the natural urban framework and comply with the ecological aspects of urban environment management, i. e., at producing urbanecological solutions. An essential condition for the offers and variant under consideration is the elaboration thereof with assessment of achievable social, economic and environmental effects. In the territory of Rostov-on-Don, the most practicable step is taking measures for arrangement and planning in the course of urban development reconstruction. The main measures may include:

1. removal of the airport outside the city limits;

2. arrangement of traffic network in a way providing for an uninterrupted movement of vehicles within the city limits;

3. road traffic control, limitation of rod works at night, etc.;

4. noise-protective vitrification;

5. sound insulation of facades facing the noise source (this can be achieved by heat insulation of the facades which will give a double positive effect);

6. installation of noise protection screens along thoroughfares and railways;

7. application of new sorts and technologies of coating with noise-insulation effect in reconstruction and construction of road network;

8. planting in free areas in order to achieve the psychological effect of noise insulation.

Installation of a screening wall is a difficult measure: this screen has to be integrated into the architectural appearance of the existing development. Rostov-on-Don is the city with more than one million dwellers and complete development. This fact complicates the work of reduction of the noise load to the normative values. A hindrance here is the allocation of a plot for installation of the screen of a considerable length. In case that the administrative and arrangement measures do not suffice, and the installation of screening wall is impossible, the next most likely variant is the installation of noise-protective glass panes [9].

In case of new construction, it will be necessary to elaborate the zoning of the space on the stage of detailed planning, taking into account the noise pollution level; the noise barriers must then be placed so that the noise-protected edifices would be in the first range of development, and the residential houses, healthcare institution, schools, kindergartens and place for recreation would be placed in the second and any consequent range of development in the neighborhoods. 
A motivation to change the environment properties towards the sustainable improvement thereof shall serve as a basis for elaboration of the range of strategies, including a strategy of red and green zones, environmental and landscaping strategy, priority development strategy, public spaces strategy, transport strategy, mixed use strategy, blocks strategy, heritage strategy and peripheral spaces strategy .

Overcoming the existing lack of coordination the work of urban planners, architects and builders in order to ensure the required quality of the urban environment under formation, is difficult to imagine without the improvement of approaches towards the normative regulation of issues of territory artificialisation, possibility to take a variety of measures that must be addressed by developers obligatorily and included into the conditions of acceptance of objects. In relation to the reconstructed architectural objects within the structure of industrial areas where environmental issues are particularly acute, a mechanism of burdening the developer with performance of any additional landscaping arrangements of the territory with the restoration of the natural components of the environment in the form of high vegetation and the organization of green areas as places of recreation for the staff and visitors, is necessary [10]. Implementation of ecological reconstruction of all restored and reformed urban areas can become one of the main prerequisites for sustainable development of such areas.

\section{References}

1. L. Girya, S. Sheina, P. Fedyaeva, Journal of Applied Engineering Research. 8. 19263$19276(2015)$

2. Z. Ivanova, O. Yudenkova, J. Naimaviciene, MATEC 73, 07008 (2016)

3. M. Viscardi, P. Napolitano, S. Ferraiuolo, MATEC, 76, 05013 (2016)

4. S. Sheina, L. Babenko, Eastern European Scientific Journal 5, 123-127 (2013)

5. S. Sheina, A. Khamavova, Procedia Engineering 150, 1960-1965 (2016)

6. E. Shcherbina, N. Danilina, Proceedings of Irkutsk State Technical University 1, 183186 (2014)

7. I. Tsukernikov, I. Shubin, N. Ivanov, T. Nevenchannaya, Procedia Engineering 117, 362-367 (2015)

8. V. Kas'janov, A. Lyapin, O. Chernysheva, Vestnik MGSU, 8, 50-57 (2011)

9. S. Sheina, L. Babenko, Advanced Materials Research 1044-1045, 1517 (2014)

10. P. Grabovy, A. Naumov, I. Avilova, International Business Management 10, 1354$1364(2016)$ 